\title{
The Relationship between Agricultural Carbon Emissions and Agricultural Economic Growth and Policy Recommendations of a Low-carbon Agriculture Economy
}

\author{
Chuanhe Xiong ${ }^{1,2}$, Degang Yang ${ }^{1 *}$, Jinwei Huo ${ }^{1}$, Yannan Zhao ${ }^{1,2}$ \\ ${ }^{1}$ Xinjiang Institute of Ecology and Geography, Chinese Academy of Sciences, \\ Urumqi 830011, China \\ ${ }^{2}$ University of Chinese Academy of Sciences, Beijing 100049, China
}

Received: 22 March 2016

Accepted: 5 May 2016

\begin{abstract}
We applied decoupling relationship analysis in this study to explore the relationship between agricultural carbon emissions and agricultural economic growth using data from Hotan prefecture in 1999-2013. The results demonstrated:

1. During 1999-2013 the decoupling index between agricultural carbon emissions and agricultural economic growth showed a "decoupling, hooking, and decoupling" three-state process. This was in the relative decoupling stage between 1999 and 2004, the relative hook state between 2005 and 2009, and the relative decoupling stage between 2010 and 2013. According to the elastic index, the relationship was in a strong decoupling state between 2000 and 2002, a weak decoupling state between 2003 and 2004, an expansive negative decoupling state between 2005 and 2009, and a weak decoupling state between 2010 and 2013.

2. Hotan is an area whose carbon emissions intensity is higher than that of the China and Xinjiang regions, is a serious lag on the decoupling stage to the nation and the region, and cannot achieve its agricultural carbon emission reduction targets by 2030. Therefore, a low carbon agriculture economy is the best strategic choice to develop its economy and address global climate change in Hotan.

Thus, we have proposed policy recommendations including the establishment of a low carbon sense, the change of agricultural development way, the development of agricultural S\&T, and the establishment of an incentive mechanism.
\end{abstract}

Keywords: Hotan prefecture, agricultural carbon emissions, agricultural economic growth, decoupling relationship analysis, low-carbon agriculture economy

*e-mail: dgyang@ms.xjb.ac.cn 


\section{Introduction}

Climate change has already become the most serious global environmental problem [1]. The increasing concentrations of $\mathrm{CO}_{2}, \mathrm{~N}_{2} \mathrm{O}, \mathrm{CH}_{4}$, and other greenhouse gases in the atmosphere constitute the most important roots of global warming [2-4]. Based on this background, a "low-carbon economy" with low energy consumption, low pollution, and low greenhouse gas emissions comes into being with the goal of realizing the decoupling of economic growth and greenhouse gas emissions. Therefore, more and more scholars have begun to pay close attention to the relationship between economic development and carbon emissions and carry out indepth studies. These studies focus on the relationship between economic growth and carbon emissions [5-8], the relationship between foreign trade and carbon emissions [9-12], and the relationship between economic growth, energy consumption, and carbon emissions [13-19].

It is known that the study of the relationship between economic growth and carbon emissions has been fruitful through an overview of the literature noted above, which greatly enhances our understanding of the relationship between economic growth and carbon emissions, and more important is providing theoretical and data support for the government to correctly handle the relationship between economic growth and carbon emissions by formulating scientific and reasonable carbon emission mitigation policies. But at the same time, the current research also has some shortcomings, such as more scholarly focus on the relationship between economic growth and energy carbon emissions, as few people pay close attention to agricultural carbon emissions. Even when considering agricultural carbon emissions, scholars only discuss the relationship between agricultural carbon emissions and economic growth [20], and almost no one considers the relationship between agricultural carbon emissions and agricultural economic growth. As a matter of fact, agriculture is the important source of greenhouse gases. Although agricultural carbon emissions are less than the second and third industry, its spatial distribution and development speed are important causes of climate warming. The emissions of greenhouse gases in the global agricultural ecosystem accounted for $13.5 \%$ of the world's total greenhouse gas emissions [21], and the emissions of greenhouse gases in China's agricultural ecosystem accounted for about $17 \%$ of China's total carbon emissions [22], which is responsible for $>20 \%$ of global agricultural GHG [21]. $\mathrm{CH}_{4}$ and $\mathrm{N}_{2} \mathrm{O}$ from agriculture account for $50 \%$ and $92 \%$ of China's total $\mathrm{CH}_{4}$ and $\mathrm{N}_{2} \mathrm{O}$ emissions, respectively [23]. Thus it is not scientific to neglect the agricultural carbon emissions in the study of carbon emissions, and it is not reasonable only to consider the relationship between economic growth and agricultural carbon emissions. Because the agricultural production sector has its own special nature, its changing track is not entirely consistent with the national economy, and we should study the relationship between agricultural economic growth and agricultural carbon emissions.
At present, there is not a unified definition of "low carbon agriculture," and different scholars have different expressions. Wang Yun said that a low-carbon agricultural economy should be a low energy consumption, low pollution, and low greenhouse gas emission economy - its essence being economical, efficient, and safe [24]. Luo Shiming put forward that a low-carbon agriculture economy is a bio-diverse agriculture economy that could avoid the use of pesticides, fertilizers, etc. [25]. Weng Boqi pointed out that a low-carbon agricultural economy should highlight the efficient use of resources, green product development, the development of an eco economy, scientific and technological progress, industrial upgrading, and carbon sequestration [26]. Combined with previous research results, we believe that a lowcarbon agriculture economy is a reflection of a lowcarbon economy in agricultural production, and is the improvement and sublimation of traditional agriculture, with the idea of "low carbon" as the core that stresses energy conservation and emission reduction, carbon sequestration technologies, clean energy theory to guide agricultural production practice, achieve the goal of agricultural production ("low energy consumption, low pollution, low emission, high efficiency"), and ultimately achieve the protection of the ecological environment and the improvement of environmental quality. It can be seen that the concept of low-carbon agriculture is similar to the concepts of sustainable agriculture, ecological agriculture, and circular agriculture. Through a low-carbon agriculture economy we can reduce damage to natural resources and improve the environment; meanwhile, we can also promote farmers' incomes, promote rural economic rapid development, and realize sustainable agricultural development.

Xinjiang's Hotan prefecture, located in the southernmost tip of the Xinjiang Uygur Autonomous Region, covers a total area of $248,100 \mathrm{~km}^{2}$. It is a region with a backward economy, a fragile environment, and is dominated by an agricultural economy whose production is backward under extensive management [27]. Therefore, it is particularly necessary to explore the relationship between agricultural carbon emissions and agricultural economic growth, and to develop a low-carbon agriculture economy. This paper applied decoupling theory to analyze the relationship between agricultural carbon emissions and agricultural economic growth, and policy recommendations for a low-carbon agriculture economy are proposed in order to correctly handle the relationship between agricultural carbon emissions and agricultural economic growth.

\section{Material and Methods}

\section{Calculation Method of Agricultural Carbon Emissions}

On the basis of some researchers' carbon emission equations $[28,29]$, this paper has constructed an agricultural carbon emissions formula as follows: 


$$
C=\sum C_{i}=\sum T_{i} \mu_{i}
$$

...where $C$ is total carbon emissions, $C_{i}$ is the carbon emissions of carbon source $i, T_{i}$ is the amount of carbon source $i$, and $\mu_{i}$ is the carbon emission coefficient of carbon source $i$. Three types of greenhouse gases have been examined in this paper: $\mathrm{C}, \mathrm{CH}_{4}$, and $\mathrm{N}_{2} \mathrm{O}$. In order to facilitate the analysis, we replaced $\mathrm{CH}_{4}$ and $\mathrm{N}_{2} \mathrm{O}$ with standard $\mathrm{C}$ in the final calculation (according to IPCC) [1], and so all of those greenhouse gas emissions were named carbon emissions.

In accordance with the results of past research [29-31] and expert suggestions, we calculate the carbon emissions of agricultural land use (carbon emissions directly or indirectly caused by agricultural material inputs such as chemical fertilizer, pesticides, plastic sheeting, agricultural diesel, soil organic carbon released from agricultural land, and carbon emissions caused by agricultural irrigation), and $\mathrm{CH}_{4}$ gas emissions produced during the growth and development of rice and carbon emissions from livestock farming (livestock breeding is another important source of $\mathrm{N}_{2} \mathrm{O}$ and $\mathrm{CH}_{4}$, which mainly includes the $\mathrm{CH}_{4}$ emissions caused by enteric fermentation and the discharge of $\mathrm{CH}_{4}$ and $\mathrm{N}_{2} \mathrm{O}$ during livestock manure management). All the carbon sources and coefficients in this paper are from the research of Xiong Chuanhe [30].

\section{Decoupling Theory and Method}

Decoupling theory was proposed by scholars to solve issues regarding the dependence of economic growth on material consumption [32]. The World Bank's decoupling concept (delinking) includes both dematerialization and depollution and refers to the process of gradually reducing the effects of economic activities on the environment [33]. However, the decoupling concept of the Organization for Economic Cooperation and Development (OECD) is being more widely cited. The OECD states that decoupling involves breaking the link between environmental "bads" and economic "goods" [34], or the link between environmental pressure and economic performance [35-36]. In the 1990s, the OECD first applied the decoupling theory to agricultural policy research; now it is applied to various fields. The main applications involve the relationship between the decoupling of economic growth and pollution emissions, material flow, waste and energy [37-40,34], the decoupling relationship between the output or economic growth of certain sectors (energy, transportation, agriculture, manufacturing, etc.) and the corresponding environmental impact [41-43], decoupling analysis regarding land resources [44-47], the comparative study for the decoupling conditions of different regions [48], and decoupling policy [49-50].

Decoupling measurement methods include comprehensive analysis, the decoupling index, elastic analysis, and descriptive statistics analysis [51]. In this paper we used the decoupling index and elastic analysis.
The Decoupling Index Method

On the basis of the research of OECD [52] and Xiong [19], we established the formulae describing the decoupling index between agricultural economic growth and agricultural carbon emissions:

$$
\begin{aligned}
\text { DIn } & =\frac{\text { CIn }}{\text { AGIn }} \\
\text { CIn } & =\frac{\mathrm{Cn}}{\mathrm{C} 0} \\
\text { AGIn } & =\frac{\text { AGDPn }}{\text { AGDP0 }}
\end{aligned}
$$

...where DIn is the decoupling index between agricultural economic growth and agricultural carbon emissions at time $\mathrm{n}, \mathrm{CIn}$ is the agricultural carbon emission index at time n, AGIn is the agricultural added value growth index at time $\mathrm{n}, \mathrm{Co}$ is the total agricultural carbon emissions at the base time, $\mathrm{Cn}$ is the total agricultural carbon emissions at time n, AGDPo is the agricultural added value at the base time, and AGDPn is the agricultural added value at time $\mathrm{n}$. In this paper, the base time is the year 1999. When $\mathrm{DI} \geq 1$, the agricultural carbon emission growth rate and agriculture economic growth rate are synchronous, or the agricultural carbon emissions growth rate is higher than the rate of agriculture economic growth; this relationship indicates that there is no occurrence of decoupling, which is denoted as the absolute hook. When $0<\mathrm{DI}<1$, the agricultural carbon emission growth rate is lower than the rate of agriculture economic growth, which is denoted as relative decoupling $[51,37]$.

\section{The Elastic Analysis Method}

The elastic analysis method is mainly used to measure the degree of elastic decoupling. This decoupling method was proposed for the decoupling analysis of traffic and GDP [50, 35]. In this paper, by integrating the comprehensive analysis method of Vehmas [48] and the elastic analysis method of Tapio [53], we established the formula describing the decoupling elasticity index of agricultural economic growth and agricultural carbon emissions:

$$
\mathrm{cg}=\% \Delta \mathrm{C} / \% \Delta \mathrm{AGDP}=\frac{\mathrm{Cn} / \mathrm{C} 0-1}{\mathrm{AGDPn} / \mathrm{AGDP} 0-1}
$$

...where $\mathrm{cg}$ is the decoupling elasticity index, $\Delta \mathrm{C}$ indicates the change in agricultural carbon emission from the base time to time n, $\triangle \mathrm{AGDP}$ indicates the difference in agricultural added value from the base time to time $n$, Co is the total agricultural carbon emissions at the base time, En is the total agricultural carbon emissions at time $\mathrm{n}, \mathrm{AGDPo}$ is the agricultural added value at the base time, and AGDPn is the agricultural added value at time $n$. 
Again, the base time in this paper is 1999 . There are six types of decoupling elasticity indices (Fig. 1) [51, 53-54]:

- Strong decoupling, when the agricultural economy rises and agricultural carbon emissions decrease.

- Strong negative decoupling, when the agricultural economy declines and agricultural carbon emissions increase.

- Weak decoupling, when the agricultural economy rises and agricultural carbon emissions increase, but the agricultural carbon emission growth rate is lower than the rate of agricultural economic growth.

- Expansive negative decoupling, when the agricultural economy rises, the agricultural carbon emission increases and the agricultural carbon emission growth rate is higher than the rate of agricultural economic growth.

- Weak negative decoupling, when the agricultural economy declines, the agricultural carbon emission decreases, and the agricultural carbon emission growth rate is higher than the rate of agricultural economic growth.

- Recessionary decoupling, when the agricultural economy declines and the agricultural carbon emission decreases, but the agricultural carbon emission growth rate is lower than the rate of agricultural economic growth.

\section{Data Sources and Processing}

The data in this study come from the Hotan prefecture statistical yearbooks (2000-14). Taking into account the fact that the agricultural production value that was calculated in actual price couldn't be compared longitudinally, we served 2000 as the benchmark year of price by using a comparable price of GDP.

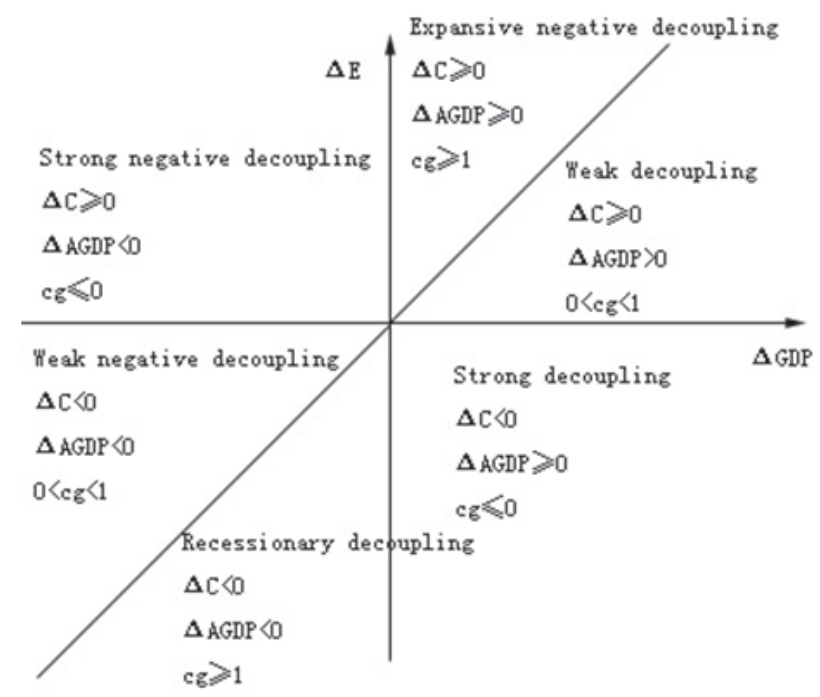

Fig. 1. Decoupling degrees model of agricultural carbon emissions and agricultural economic growth (decoupling elasticity index).

\section{Results}

Decoupling Relationship Analysis between Agricultural Carbon Emissions and Agricultural Economic Growth

Using formulae 1-5 we obtained the dynamic relationship between agricultural carbon emissions and the agricultural economic growth in Hotan prefecture based on a data consolidation calculation (Table 1). According to the results of the decoupling analysis, Hotan prefecture's agricultural economic development can be divided into three stages: the first stage (1999-2004), the second stage (2005-09) and the third stage (2010-13).

For the first stage (Table 1), the agricultural carbon emission index decreased first and then increased from 1999 to 2004, with the lowest point occurring in 2002. The agricultural added value growth index fluctuated during the same period. The decoupling index decreased first and then increased during the same period, and this period was in the relative decoupling stage. Based on the elastic index, $\Delta \mathrm{C}<0, \Delta \mathrm{AGDP}>0$, and $\mathrm{cg}<0$ from 2000 to 2002, indicating strong decoupling; and $\Delta \mathrm{C}>0, \Delta \mathrm{AGDP}>0$, and $0<\mathrm{cg}<1$ from 2003 to 2004 , indicating weak negative decoupling.

For the second stage (Table 1), the agricultural carbon emission index rose rapidly from 2005 to 2009 and the agricultural added value growth index increased slowly during this period. The decoupling index fluctuated during the same period, which remained between 1.02 and 1.12 (the relative hook state). Based on the elastic index, $\Delta \mathrm{C}>0$, $\triangle$ AGDP $>0$, and cg $>1$ between 2005 and 2009, indicating an expansive negative decoupling state.

For the third stage (Table 1), the agricultural carbon emission index decreased slowly from 2010 to 2013 while the agricultural added value growth index increased rapidly during this period. The decoupling index decreased rapidly during 2010-13, which was 0.96 in 2010 and then decreasing to 0.79 in 2013; this period was in the relative decoupling stage. Based on the elastic index, $\Delta \mathrm{C}>0, \Delta \mathrm{AGDP}>0$, and $0<\mathrm{cg}<1$ between 2010 and 2013, corresponding to the weak decoupling state.

During the period 1993-2010, the decoupling index between agricultural carbon emissions and the agricultural economic growth showed the three stages of the change of "decline, rise, and decline" (Fig. 2), and experienced a "decoupling, hooking, and decoupling" three-state process. The relationship between agricultural carbon emissions and agricultural economic growth was in the relative decoupling stage between 1999 and 2004, a relative hook state between 2005 and 2009, and a relative decoupling stage between 2010 and 2013. According to the elastic index, the relationship between agricultural carbon emissions and agricultural economic growth was in a strong decoupling state between 2000 and 2002, a weak decoupling state between 2003 and 2004, an expansive negative decoupling state between 2005 and 2009, and a weak decoupling state between 2010 and 2013 (Table 1). 
Table 1 Decoupling analysis result about agricultural carbon emissions and agricultural economic growth.

\begin{tabular}{|c|c|c|c|c|c|c|c|c|c|}
\hline Year & Cn (10 tons $)$ & AGDPn $\left(10^{8}\right.$ yuan $)$ & CIn & GIn & DIn & $\Delta$ C & $\Delta$ AGDP & cg & Decoupling state \\
\hline 1999 & 59.20 & 15.13 & 1.00 & 1.00 & 1.00 & 0.00 & 0.00 & - & - \\
\hline 2000 & 58.44 & 15.92 & 0.99 & 1.05 & 0.94 & -0.01 & 0.05 & -0.24 & Strong decoupling \\
\hline 2001 & 58.54 & 15.84 & 0.99 & 1.05 & 0.94 & -0.01 & 0.05 & -0.24 & Strong decoupling \\
\hline 2002 & 56.76 & 16.47 & 0.96 & 1.09 & 0.88 & -0.04 & 0.09 & -0.46 & Strong decoupling \\
\hline 2003 & 59.57 & 15.87 & 1.01 & 1.05 & 0.96 & 0.01 & 0.05 & 0.13 & Weak decoupling \\
\hline 2004 & 62.72 & 16.26 & 1.06 & 1.07 & 0.99 & 0.06 & 0.07 & 0.79 & Weak decoupling \\
\hline 2005 & 66.92 & 16.77 & 1.13 & 1.11 & 1.02 & 0.13 & 0.11 & 1.20 & Expansive negative decoupling \\
\hline 2006 & 70.38 & 16.03 & 1.19 & 1.06 & 1.12 & 0.19 & 0.06 & 3.15 & Expansive negative decoupling \\
\hline 2007 & 71.67 & 17.19 & 1.21 & 1.14 & 1.07 & 0.21 & 0.14 & 1.55 & Expansive negative decoupling \\
\hline 2008 & 73.68 & 18.28 & 1.24 & 1.21 & 1.03 & 0.24 & 0.21 & 1.17 & Expansive negative decoupling \\
\hline 2009 & 76.41 & 19.21 & 1.29 & 1.27 & 1.02 & 0.29 & 0.27 & 1.08 & Expansive negative decoupling \\
\hline 2010 & 79.29 & 21.00 & 1.34 & 1.39 & 0.96 & 0.34 & 0.39 & 0.87 & Weak decoupling \\
\hline 2011 & 81.04 & 22.17 & 1.37 & 1.47 & 0.93 & 0.37 & 0.47 & 0.79 & Weak decoupling \\
\hline 2012 & 80.03 & 23.20 & 1.35 & 1.53 & 0.88 & 0.35 & 0.53 & 0.66 & Weak decoupling \\
\hline 2013 & 78.10 & 25.21 & 1.32 & 1.67 & 0.79 & 0.32 & 0.67 & 0.48 & Weak decoupling \\
\hline
\end{tabular}

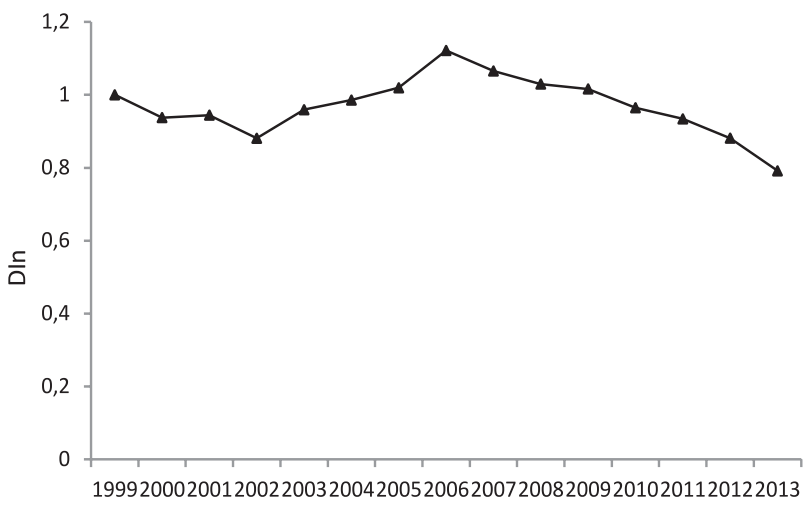

Fig. 2. Decoupling index (DIn) of agricultural carbon emissions and agricultural economic growth in Hotan prefecture.

\section{Discussion}

Regarding the decoupling relationship analysis between agricultural carbon emissions and agricultural economic growth:

1. For the first stage (1999-2004), which was in a strong decoupling state between 2000 and 2002 and a weak decoupling state between 2003 and 2004, the agricultural carbon emissions fluctuated. There were three reasons for the change of the first stage: first, the agricultural production structure began to change - from the production structure of planting industry, animal husbandry, characteristic forestry, and fruit industry to the production structure of characteristic forestry and fruit industry, animal husbandry and planting industry - the result was the reduction of agricultural material inputs. Second, due to meat product prices declining, the number of livestock declined; third, cotton was affected by prices in 2002 as plant area changed from $4.09 \times 10^{4}$ hectares in 2001 to $1.69 \times 10^{4}$ hectares in 2002 , total area decreased by $2.4 \times 10^{4}$ hectares and decreased by $58.80 \%$. The result is a significant reduction in the use of chemical fertilizers, pesticides, and plastic sheeting. However, Hotan's agricultural economy grew slowly (Table 1) because its agricultural production pattern was alternating forest and agricultural crop.

2. The second stage (2005-09) was an expansive negative decoupling state. This stage was in the middle of the agricultural production structure transformation. With rapid development of characteristic forestry and fruit industry and fruit trees in the fruiting stage, agricultural material inputs increased, resulting in the rapid increase of carbon emissions of agricultural land use; on the other hand, the amount of livestock breeding had continued to increase, resulting in a substantial increase in carbon emissions of livestock husbandry. Thus, agricultural carbon emissions continued to rise. But Hotan's agricultural economy grew slowly and its agricultural production pattern was alternating forest and agricultural crop. The income of characteristic forestry and the fruit industry increased, but planting industry income was reduced. Meanwhile, China abolished the agricultural tax in 2006, which increased the enthusiasm of farmers. As a result, the agricultural economy and agricultural carbon emissions increased, but the agricultural carbon emission growth rate was higher than the rate of agricultural economic growth. This was the reason for the relationship between 
agricultural carbon emissions and agricultural economic growth in the expansive negative decoupling state.

3. The third stage (2010-13) was in a weak decoupling state. Hotan had formed the production structure of characteristic forestry and the fruit industry, animal husbandry, and the planting industry at this stage [30] and its agricultural production pattern was alternating forest and agricultural crop. Fruit trees were in a period of fruit production and agricultural material inputs were relatively stable, but the yield of wheat and corn was further reduced. Family livestock feed in Hotan prefecture was given priority with wheat and maize straw. As a result, it led to a serious shortage of forage and the amount of livestock decreased year by year. What's more, with the development of agricultural science and technology (S\&T), efficiency improved continuously in this stage. Thus, agricultural carbon emissions decreased. However, the agricultural economy developed rapidly during this period because fruit production increased year by year with a higher price, and the aid of Beijing led to the rapid development of forestry and fruit products.

In the past 15 years the relationship between agricultural carbon emissions and the agricultural economy in Hotan is mainly in the expansive negative decoupling state. Meanwhile, the relationships between agricultural carbon emission and agricultural economy in China and Xinjiang are mainly in a strong decoupling state and a weak decoupling state [55-56]. This indicates that Hotan is seriously lagging as regards the regional and national decoupling stages.

Based on historical data, we used the annual agricultural economic growth rate of $3.72 \%$, averaged over 15 years, as the pre-economic growth rate between 2014 and 2030. Moreover, we used the lowest level (0.79) of the decoupling index over the past 15 years as the scenario predictions for the period 2014-30. The results show that total agricultural carbon emissions will be $145.01 \times 10^{4}$ tons and the agricultural output value will be $46.90 \times 10^{8} \mathrm{CNY}$ in 2030 , and its $\mathrm{CO}_{2}$ emissions per unit of $10,000 \mathrm{CNY}$ agricultural output value will decrease by $22.56 \%$ compared with 2005, while China has proposed that by 2030 its $\mathrm{CO}_{2}$ emissions per unit of GDP will have decreased by 60-65\% compared with 2005 . Hotan's agricultural carbon emission reduction task is arduous.

\section{Policy Recommendations of a Low-Carbon Agricultural Economy}

Through the foregoing decoupling relationship analysis, we know that Hotan is a serious lag on the regional and national decoupling stages, and that it cannot achieve its agricultural carbon emission reduction targets by 2030. Meanwhile, Hotan's agricultural carbon emissions intensity is higher than for the region and the nation [30, 56-57]. What's more, Hotan is a region with a fragile environment. Therefore, Hotan should speed up the pace of agricultural carbon emission reduction and develop a low-carbon agriculture economy that could reduce the damage to natural resources and improve the ecological environment while at the same time promoting farmer incomes and rural economic rapid development, and realizing sustainable agricultural development.

In order to reduce agricultural carbon emissions, Hotan should pay more attention to the following three issues:

1. The level of development of agricultural S\&T is low, and agriculture-related R\&D investment is little.

2. Farmers usually plant crops, raise livestock, and use the agrochemical inputs in an inefficient way only because they lack knowledge and experience.

3. Hotan lacks an incentive mechanism to promote the development of low carbon agriculture. Therefore, it should accelerate the development of agricultural S\&T and set up an incentive mechanism to promote the development of low-carbon agriculture.

Thus, we propose the following policy recommendations for a low-carbon agricultural economy:

1. Setting up a sense of low-carbon economy and changing the method of agricultural development. Education development lags behind, with the cultural level of the middle school population accounting for $74.85 \%$ of the rural population in Hotan [27]. Therefore, Hotan should increase publicity so that the majority of farmers fully understand the complexity and long-term nature of climate change, profoundly understand the role of agriculture regarding the doubleedged sword of climate change, and set up a sense of a low-carbon economy. In changing the method of agricultural development [30, 34], Hotan must abandon the traditional development thinking and mode of development, completely change the ideas of paying more attention to development but neglecting savings, paying more attention to the speed of development but neglecting the benefit and one-sided pursuit of GDP growth, but neglecting resources and the environment. Hotan should accelerate the development of lowcarbon agriculture, consider the development of economic, social and ecological benefits in agricultural production, and promote comprehensive coordination and sustainable development of the agricultural economy and climate, resources, and the environment.

2. Strengthening S\&T innovation. First of all, more agriculture-related R\&D investment should be made. Then Hotan should increase the intensity of science research and technology integration of assembling complete sets, continue to carry out research of lowcarbon agricultural technology for conserving land, saving water, reducing the use of fertilizers, reducing the use of pesticides, saving energy, and reducing agricultural waste generation [30].

3. Strengthening S\&T promotion and improving S\&T guidance and support of low-carbon agriculture. Farmers want and need professional and technical guidance. More agriculture-related R\&D investment should be directed toward attracting skilled technicians in order to make agricultural technology promotion 
and skills training popular. Hotan should introduce a variety of low-carbon agricultural technology and carry out various technical guidance and training for low-carbon agriculture, including planting and livestock breeding [30, 58-60].

4. Setting up the ecological compensation mechanism of agricultural carbon sinks. The agricultural carbon sink compensation mechanism is an important incentive mechanism to promote the development of low-carbon agriculture. The aim of this mechanism is to reduce carbon emissions and increase carbon sink, and reduce damage to natural resources and improve the ecological environment while promoting farmer incomes, and rural economic rapid development, and realizing agricultural sustainable development. Most important is being conducive to the formation of a bottom-up low-carbon movement. Therefore, in order to reduce agricultural carbon emissions, Hotan should set up the ecological compensation mechanism of agricultural carbon sinks using the following components: the main body of compensation, the compensation principle, the compensation method, and the compensation standard.

\section{Conclusions}

The present study explored the relationship between agricultural carbon emissions and agricultural economic growth using data from Hotan prefecture over the period of 1999-2013. The results show that a low-carbon agricultural economy is the best strategic choice to develop its economy and address global climate change in the prefecture.

During 1993-2010, the decoupling index between agricultural carbon emissions and agricultural economic growth showed the three stages of the change of "decline, rise, and decline" and experienced a "decoupling, hooking, and decoupling" three-state process. The relationship between agricultural carbon emissions and agricultural economic growth was in the relative decoupling stage between 1999 and 2004, a relative hook state between 2005 and 2009, and a relative decoupling stage between 2010 and 2013. According to the elastic index, the relationship between agricultural carbon emissions and agricultural economic growth was in a strong decoupling state between 2000 and 2002, a weak decoupling state between 2003 and 2004, an expansive negative decoupling state between 2005 and 2009, and a weak decoupling state between 2010 and 2013 .

Through the foregoing analysis, we know that Hotan is an area whose carbon emissions intensity is higher than that of the China and Xinjiang regions, and is a serious lag on the regional and national decoupling stages. Therefore, Hotan should speed up the pace of agricultural carbon emissions reduction and develop a low-carbon agricultural economy that can reduce damage to natural resources and improve the ecological environment while at the same time promoting the farmer incomes and rapid rural economic development, and realizing sustainable agricultural development. Needless to say, a low-carbon agriculture economy is the best strategic choice to develop its economy and address global climate change in Hotan. We thus propose policy recommendations, including the establishment of a low-carbon sense, the changing agricultural development methods and the development of agricultural S\&T, and establishing an incentive mechanism.

\section{Acknowledgements}

This work was supported by the Study on Oasis Population Evolution and Transfer Way: A Case in Moyu County (XBBS-2014-11). The authors would like to thank Hotan prefecture for assistance with data collection.

\section{References}

1. IPCC. Climate Change 2007: Synthesis Report. Contribution of Working Groups I, II and III to the Fourth Assessment Report of the Intergovernmental Panel on Climate Change [Core Writing Team, Pachauri, R.K and Reisinger, A. (eds.)]. IPCC, Geneva, Switzerland, 104, 2007.

2. IPCC. Climate Change 1995. The Science of Climate Change. The Contribution of Working Group I to the Second Assessment Report of the Intergovernmental Panel on Climate Change. Cambridge University Press, New York. 1996.

3. WANG Q.W., ZHOU P., GE S.L., ZHAO Z.Y. An international comparison of carbon dioxide emission performance using the nonparametric metafrontier approach. Polish Journal of Environmental Studies. 23 (3), 923,2014.

4. WROBEL-JEDRZEJEWSKA M., STEPLEWSKA U., KULETA P., PRZYBYSZ L., POLAK E. Carbon footprint of fruit faste technology. Polish Journal of Environmental Studies. 25 (1), 341, 2016.

5. KAYA Y. Impact of carbon dioxide emission control on GNP growth: interpretation of proposed scenarios/IPCC Energy and Industry Subgroup, Response Strategies Working Group, Paris. 1990.

6. HOLTZ-EAKIN D., SELDEN T.M. Stoking the fires? $\mathrm{CO}_{2}$ emissions and economic growth. Journal of Public Economics. 57, 85, 1995.

7. SAJAL G. Examining carbon emissions economic growth nexus for India: A multivariate cointegration approach. Energy Policy. 38, 3008, 2010.

8. de FREITAS L.C., KANEKO S.Decomposing the decoupling of $\mathrm{CO}_{2}$ emissions and economic growth in Brazil. Ecological Economics. 70 (8), 1459, 2011.

9. COLE M.A. Does trade liberalization increase energy use? Eco. Lett. 92,108, 2006.

10. HALICIOGLU F. An Econometric Study of $\mathrm{CO}_{2}$ Emission, Energy Consumption, Income and Foreign Trade. MPRA Paper 1, 1457, 2010.

11. DEDEOGLU D., KAYA H. Energy use, exports, imports and GDP: new evidence from the OECD countries. Energy Policy . 57, 469, 2013.

12. MENSAH J.T. Carbon emissions, energy consumption and output: A threshold analysis on the causal dynamics in emerging African economies. Energy Policy. 70, 172, 2014. 
13. STERN D.I. Energy and economic growth in the U.S.A. Energy Economics . 15, 137,1993.

14. WANG H.P., TIAN P., JIN P. The study of the relationship between Chinese energy consumption and economic growth based on time varying parameter model. Application of Statistics and Management. 25 (3), 253, 2006.

15. HUANG B.N., HUANG M.J., YANG C.W. Causal relationship between energy consumption and GDP growth revisited: a dynamic panel data approach. Ecological Economics. 67 (1), 41, 2008.

16. APERGIS N., PAYNE J.E. Energy consumption and economic growth in Central America: evidence from a panel cointegration and error correction model.Energy Economics. 31, 211, 2009.

17. ACARAVCI A., OZTURK I. On the relationship between energy consumption, $\mathrm{CO}_{2}$ emissions and economic growth in Europe. Energy . 35, 5412, 2010.

18. LI F., DONG S.C., LI X., LIANG X.X.,YANG W.Z. Energy consumption-economic growth relationship and carbon dioxide emissions in China. Energy Policy. 39, 568, 2011.

19. XIONG C.H., YANG D.G.,HUO J.W., ZHAO Y.N. The relationship between energy consumption and economic growth and the development strategy of a low-carbon economy in Kazakhstan. Journal of Arid Land. 7 (5), 706, 2015.

20. LI B. Empirical study on relationship between economic growth and agricultural carbon emissions. Ecology and Environmental Sciences. 21 (2), 220, 2012.

21. NORSE D. Low carbon agriculture: objectives and policy pathways.EnvironmentDevelopment. 59, 25, 2012.

22. RAN G.H.,WANG JH, WANG D.X. Study on the carbon emissions of modern agricultural production in China .Issues in Agricultural Economy. 2, 32, 2011.

23. LI B.Agricultural carbon emissions in China: a case study of the agricultural land use. People Press, Beijing. 2013.

24. WANG Y. Low carbon agriculture economy. China Agricultural Information. 8, 12, 2008.

25. Sina agriculture. The agricultural development of China can be replaced by low-carbon agriculture. http://nongye. sina.com.cn/rollnews/20-09-1110/17185549.shtml, 200911-10.

26. Science Times. Low carbon agriculture has great potential. http://www.cas.cn/zt/hyzt/2010lianghui/2010lhsp/201003 /t-201-003082793121.html,2010-03-08.

27. Hotan Statistical Bureau.Hotan Statistical Yearbook, 2013.

28. SONG D.Y., LU Z.B.The Factor Decomposition and Periodic Fluctuations of Carbon Emission in China. China Population, Resources and Environment. 19 (3), 18, 2009.

29. TIAN Y.,ZHANG JB, HE Y.Y. Research on Spatial-Temporal Characteristics and Driving Factor of Agricultural Carbon Emissions in China. Journal of Integrative Agriculture. 13 (6), 1393, 2014.

30. XIONG C.H., YANG D.G.,HUO J.W. Spatial-temporal characteristics and LMDI-based impact factor decomposition of agricultural carbon emissions in Hotan Prefecture, China. Sustainability, 8 (3), 262:1-14, 2016.

31. JOHNSON J.MF. Agricultural opportunities to mitigate greenhouse gas emissions. Environmental Pollution. 150, 107, 2007.

32. PANG J.X., CHEN X.P., WANG H.Y. Relationship of energy consumption with economic growth in Gansu province. Journal of Arid Land Resources and Environment. 28 (2), 31, 2014.

33. DEBRUYN S.M., OPSCHOOR J.B.. Developments in the throughput-income relationship: Theoretical and empirical observations. Ecological Economics. 20 (3), 255, 1997.
34. OECD. Analysis of the links between transport and economic growth. Paris: OECD: 11.2003.

35. ENEVOLDSEN M.K., RYELUND A.V., ANDERSEN M.S. Decoupling of industrial energy consumption and $\mathrm{CO}_{2}-$ emissions in energy-intensive industries in Scandinavia. Energy Economics. 29 (4), 665, 2007.

36. LU I.J., LIN S.J., LEWIS C. Decomposition and decoupling effects of carbon dioxide emission from highway transportation in Taiwan, Germany, Japan and South Korea. Energy Policy. 35 (6), 3226, 2007.

37. HUTTLER W., SCHANDEL H., WEISZ H. Are industrial economies on the path of dematerialization? Material flow accounts for Austria 1960-1996: Indicators and international comparison. Centre of Environmental Science. Ecologizing Societal Metabolism: Designing Scenarios for Sustainable Materials Management. Amsterdam, The Netherlands: Universitair Grafisch Bedrijf Leiden, 26, 1999.

38. WANG C.M. Analyzing decoupling of economic growth and energy consumption based on the sample of China. Journal of Shandong Institute of Business and Technology. $6(1-3), 8,2009$.

39. WANG H., WANG J.Q., ZHAO T. Decoupling and recoupling analysis of China's economic development and environments and energy consumption. Statistics and Decision. 17, 113, 2009.

40. YU F.W. Decoupling analysis of economic development and environments \& resource. Journal of Inner Mongolia Finance and Economics College. 3, 29, 2009.

41. OECD. Environmental indicators-Development, measurement and use. Paris: OECD: 13, 2003.

42. ZHAO Y.P., SUN Q.H., DUAN N. Responsive relationship between economic development and energy consumption in China - a practical research based on comparative de-link and re-link theory. Science Research Management. 27 (3), 128, 2006.

43. YU F.W. Analysis of the decoupling relationship between grain production and irrigation water of China. Chinese Rural Economy. 10, 34, 2008.

44. CHEN B.M., DU H.L. Analyzing decoupling relationship between arable land occupation and GDP growth. Resources Science. 28 (5), 36, 2006.

45. GUO L., YAN J.M. Study on the decoupling of cultivated land occupation by construction. China Population, Resources and Environment. 17 (5), 48, 2007.

46. LI X.S., QU F.T., GUO Z.X. Decoupling between urban and rural construction land. China Population, Resources and Environment. 18 (5), 179, 2008.

47. SONG W., CHEN B.M., CHEN X.W. Decoupling evaluation between cultivated land occupation and economic growth in Changshu City. Journal of Natural Resources. 24 (9), 1532, 2009.

48. VEHMAS J., KAIVOOJA J., LUUKKANEN J. Global trends of linking environmental stress and economic growth. Turku: Finland Futures Research Centre. 6, 2003.

49. ZHANG Z.X. Decoupling China's carbon emissions increase from economic growth: An economic analysis and policy implications [J].World Development. 28 (4), 739, 2000.

50. FEMIA A., HINTERBERGER F., LUKS F. Ecological economic policy for sustainable development potentials and domains of intervention for delinking approaches. Population\& Environment. 23 (2), 157, 2001.

51. ZHONG T.Y., HUANG X.J., HAN L. Review on the Research of Decoupling Analysis in the Field of Environments and Resource. Journal of Nature Resource. 25 (8), 1400, 2010.

52. OECD. Indicators to measure decoupling of environmental pressures for economic growth.Paris: OECD. 2002. 
53. TAPIO P. Towards a theory of decoupling: Degrees of decoupling in the EU and the case of road traffic in Finland between 1970 and 2001.Transport Policy. 12 (2), 137, 2005.

54. WU H., GU S.Z., ZHOU H., WANG X.J. Relationships between energy comsumption-carbon emissions and economic growth in Hebei Province. Resources Science. 33 (10), 1897, 2011.

55. TIAN Y.,ZHANG JB., LI B. Agricultural carbon emissions in China: calculation, spatial-temporal comparison and decoupling effects. Resources Science. 34 (11), 2097, 2012.

56. SU Y., MA HL., LI F. Xinjiang agriculture and animal husbandry carbon emissions and its decoupling relationship with agricultural economic growth. Arid land geography, 37 (5), 1047, 2014.
57. TIAN Y., ZHANG J.B., LI B. Research on regional difference and affecting factor on competitiveness of agricultural low- carbon in China. Journal of Arid Land Resources and Environment. 27 (6), 1, 2013.

58. XIE J.F., LI Y.E., DONG H.M.,HUANG H.K., YU Q. Emission of nitious oxide and ammonia from closed composting bins containing layer-hen manure. Journal of Agro-environmental Science. 21 (6), 524, 529, 2002.

59. CHEN Y., SHANG J. Estimation and Effecting Factor Decomposition of Green House Gas Emission of Animal Husbandry Industry in Four Pastoral Areas. China Population, Resources and Environment. 24 (12), 89, 2014.

60. THOMAS J., EBERHARD H., GREGOR B. Greenhouse gas emissions from animal houses and manure stores. Nutrient Cyling in Agroecosystems. 60, 133, 2001. 